\title{
ZAHOD V AFRIKI IN AFRIČANKE NA ZAHODU - IDENTITETNA POTOVANJA IN MIGRACIJE JUNAKINJ V LITERATURI AFRIŠKIH PISATELIC
}

Ključne besede: afriške pisateljice, identiteta afriške ženske, Zahod, Afrika, migracije, identitetna potovanja, modernost, tradicija

\section{Afrika na prepihu}

Afriške pisateljice se v svojih literarnih delih ukvarjajo s sedanjimi in polpreteklimi spremembami, ki se odražajo $\mathrm{v}$ afriškem vsakdanu, ter $\mathrm{z}$ vplivom teh sprememb na junakinje literarnih besedil $\mathrm{v}$ tranzicijskem času. Zanima jih spreminjanje afriške družbene realnosti, dihotomija tradicionalnega in modernega oziroma (post)kolonialnega ter dileme zahodnih in tradicionalnih vrednot, ki kličejo po redefiniranju identitete afriške ženske. Porajajo se vprašanja, kako je zahodni vpliv spremenil življenje v Afriki, na kakšen način je vzpostavljen odnos do zahodnega, v kolikšni meri je izražena kritičnost do tradicionalnega ter kakšne so specifičnosti okoliščin za ženske. Bolj ali manj izrazito poudarjena in vrednotena je vrsta zahodnih vplivov na življenje v Afriki, ki imajo posledice tako v zaznavanju prostora kot razumevanju zgodovine.

Odnos med Zahodom in Afriko je kompleksen. Po eni strani je Zahod v Afriko vnesel razkroj starih vrednot, po drugi strani pa mešanje starih in novih vrednot v ne vedno posrečenih združitvah. Stare vrednote so v več pogledih izgubile svojo vrednost oziroma so se redefinirale, vendar pa se še zdaleč niso razkrojile. $V$ mestih poteka modernizacija na razslojen način, 
razredne razlike so velike, hkrati pa se pojavljajo izjemne razlike med ruralnim in urbanim. Pogosto se pojavi motiv enačenja Zahoda z gmotnim bogastvom oziroma s tem, kako se potrošne dobrine in dobrobiti zahodne civilizacije v Afriki vrednotijo, uveljavljajo in uporabljajo. Predmeti z Zahoda so nemalokrat fetiš, biti lastnik takšnega predmeta, tudi če ne služi več svojemu prvotnemu namenu, pomeni skokovit dvig statusa ali pomik po socialni lestvici navzgor.

Značilen je dialog med Maro in njenim možem Akobijem v romanu Beyond the Horizon pisateljice Amme Darko (Darko, 1995, 35-36). Junakinja Mara, preprosta, mlada in neizobražena ženska, ki z Akobijem živi v milo rečeno nezadovoljivem odnosu, je, ko pogovor nanese na Akobijev pravljični načrt o potovanju v Evropo, takoj omehčana in očarana kot otrok. Nepojmljivost evropskega življenja za Maro priča o afriški mitologizaciji Zahoda ter dejanskem ekonomskem prepadu med Evropo ter nekaterimi afriškimi deželami in sloji. Največje Marino čudenje nastopi, ko Akobi pove, da so v Evropi tako bogati, da mečejo stran hladilnike in avtomobile. Odlomek o Marinem razmišljanju ponazarja, kako vstopa zahodna kultura $\mathrm{v}$ afriške prostore ter dobiva nove vsebine in pomene, včasih pa je razkorak med prvotno funkcijo predmeta in njegovo "afriško « rabo prikazan kot absurden, da ne rečemo škodljiv.

\begin{abstract}
Nisem mogla verjeti, da bi človek, ki bi bil pri pravi, metal stran hladilnike in avtomobile. Ah, tukaj nisi veljal nič, če nisi imel takšnih naprav. Lahko si imel televizor, ki je bil pokvarjen. Vseeno je bilo. Morda televizije sploh nisi gledal, če pa si jo, nisi nič razumel, zakaj bi jo, če je bila polna Simona Templarja, ki je tekal gor in dol in pretepal ljudi do nezavesti, jih mrtve streljal in poljubljal dolgonoge blondinke, ko sam nisi nikoli videl pištole, ničesar vedel o nečem, kar se je imenovalo Scotland Yard, in nisi nikoli videl, da bi se starši poljubili. Toda to ni bilo važno. Važno je bilo, da si imel televizijo. In če si imel poleg televizije še hladilnik in avto, potem, eh, te je od ministra ali zdravnika ločevala le še njegova angleška žena. Kamor je stopil in pljunil on, si lahko stopil in pljunil ti. ${ }^{1}$
\end{abstract}

1 "I just could not let myself believe that a person who was correct in the head would throw away fridges and cars. Ah, here if you had no such gadgets you were a nothing. You could have a television that was spoilt. It didn't matter. You probably did not even watch it, or if you did, you didn't understand anything on it for why should you if it was full of Simon Templar running up and down boxing people unconscious, shooting them dead and kissing long- 
Da so ključni simbolni predmeti v Afriki, ki potrjujejo, da človek velja toliko, kot ima, avto, televizor in hladilnik, pa tudi če ne služijo več svojemu prvotnemu namenu, temveč se ohranjajo le kot statusni predmet, je pomemben motiv v literaturi afriških pisateljic. To se izkaže tudi v kratki zgodbi Ame Ate Aidoo »Everything Counts«, ko se junakinja vrne iz Evrope, kjer je končala študij, da se sooči z Afriko, ki je prej ni (pre)poznala. Sorodnike doma, ki jih je tako boleče pogrešala, ne zanima ona sama, temveč jo sprašujejo samo po materialnih stvareh:

Kakšen avto boš pripeljala domov, Sissie? Upamo, da ne katere tistih majhnih kokosovih lupin z dvojimi vrati, ha? ... In oh, upamo, da si prinesla hladilnik. Tukaj ga dandanes enostavno ne moremo dobiti. In če ga lahko, toliko stane ... ${ }^{2}$

Sissie spozna, da je Afrika, v katero se je vrnila, brez samozavesti; ljudje nekritično in brez premisleka podlegajo zahodnim vrednotam in merilom, ki ne sodijo v okolje, ki ga pozna. Sprašuje se, ali se je vrnila v pravo deželo. Potrošništvo in zahodni ideali lepote vodijo k vnašanju zahodnih estetskih vrednot in norm, kar ženske vzpodbudi k absurdnim modnim trendom, kot so dolgolase lasulje, ki jih nosijo v tropski vročini.

Ama Ata Aidoo se tako v romanih kot v kratkih zgodbah ukvarja s težavami, s katerimi se soočata sodobna Gana in Afrika. Kljub osamosvojitvi prihaja do nenehnega in neustavljivega oblikovanja vrednot po zahodnem vzoru. Loteva se raznovrstnih tem, ki se dotikajo življenja in ženske izkušnje v postkolonialni Afriki: vplivi Zahoda na percepcijo (ženskega) telesa in norm lepote, želja biti bel/a, slediti zahodni modi, kontinuiteta (podre-

legged blonde when you yourself had not seen a gun before, knew nothing of something called Scotland Yard and had never seen your parents kiss? But that didn't matter. What mattered was that you had a television. And if as well as television you had a fridge and a car, then, eh, between you and the minister or doctor only his English wife separated you. Where he stepped and spat, you could step or spit.« (Darko, 1995, 35-36) Vse citate je prevedla avtorica članka.

2 »What car are you bringing home Sissie? We hope it is not one of those little coconut shells with two doors, heh? ... And oh, we hope you brought a refrigerator. Because you simply cannot find one here these days. And if you do, it costs so much...« (Aidoo, 1970, 4). 
jenih) vlog, ki so jih razvili za služenje belim gospodarjem, ter prepad med razredi.

Žensko telo je reprezentativen poligon za izražanje vplivov Zahoda. Junakinja Opokuya v romanu Changes je debeluška, ki s svojo, kljub vsemu nadzorovano težo, saj se odreka sladkarijam, zdravo in veselo živi ter meni, da je debelost kot negativen koncept zahodni konstrukt. V dialogu s prijateljico Esi napol v šali pravi:

Dnevi, ko je bila debelost znak blaginje in zadovoljstva, so zdavnaj mimo. Ti in jaz veva, da so dandanes edini debeli ljudje na svetu revne neizobražene ženske $\mathrm{v}$ tako imenovanem tretjem svetu ter spolnosti sestradane nesrečne ženske $\mathrm{v}$ premožnejših družbah, ki naj bi jedle za tolažbo. ${ }^{3}$

Opokuya, ki je medicinska sestra, je kritična do propagande družinskega načrtovanja, uvoženega z Zahoda skupaj z raznimi kontracepcijami, za katere meni, da so strup, ter da gre za zaroto Zahoda, ki ne želi, da bi bilo Afričanov preveč. Med svojimi sogovorniki, bolnišničnim osebjem, najde ob nasprotnikih, ki jo skušajo pregovoriti o civiliziranosti in modernosti tovrstnih postopkov, tudi nekaj tihih privržencev.

Le malo žensk se v svojih telesih počuti osvobojene, saj so jih v tem smislu zavirale številne »mednarodne« silnice: »... tradicionalna sramežljivost in zaničevanje ženske biologije; islamske zatiralne ideje o ženskah; angleško viktorijanska navidezna krepostnost in francoska hipokrizija, ki so jo uvozili kolonizatorji ...« « Ali je navdušen nad svojo ljubimko Esi, ki se ne sramuje svojega telesa in se po ljubljenju po stanovanju sprehaja gola, kajti med številnimi ženskami, ki jih je imel pred njo, v Afriki še ni srečal takšne, ki bi bila glede tega tako svobodna.

3 »The day when being fat was a sign of prosperity and contentment are long over. You and I know that these days the only fat people in the world are poor uneducated women in the so-called Third World and unhappy sex-starved women in the more affluent societies who are supposed to eat for consolation.« (Aidoo, 1991, 36)

$4 » \ldots$ traditional shyness and contempt for the biology of women; Islamic suppressive ideas about women; English Victorian prudery and French hypocrisy imported by the colonisers ...« (ibid., 75). 
Podobno Tambudzai v romanu Nervous Conditions opisuje zgodnje otroštvo kot najboljši čas za plesanje. Tedaj je, kadar se je s plesom predala glasbi, vse zabavala. Ko je začela odraščati in je glasbo bolj začutila, se njeno gibanje nikomur več ni zdelo zabavno, temveč je spoznala, da je njeno uživanje v ritmu dobilo druge, »slabe« implikacije. Tambu pravi: »Moj ples se je stisnil v toge, oklevajoče gibe. Nisem ga popolnoma opustila, toda shodi so bili odslej zame mnogo manj zabavni in na njih sem se počutila strašno nesamozavestno. $\aleph^{5}$ Sproščen ples s svojo erotično razsežnostjo ni bil več dovolj spodoben, kar je zopet v nasprotju z običaji tradicionalnih kultur, kjer se je vedno veliko in pogosto ekstatično plesalo. Golota in gibanje dobivata na mestih, kjer vstopajo katoliška ali islamska vera ter kolonialni vplivi, drugačne konotacije. Seveda se na ruralnih območjih, ki so praviloma tradicionalnejša, norme, ki določajo sprejemljivost in nesprejemljivost ženskega telesa, pogosto prepletajo.

Tudi oblačila so skušala čim bolj posnemati zahodne vzore. V zgodbi »Everything Counts« junakinja razmišlja, kako drago ljudje plačujejo rabljena ameriška oblačila. V romanu Amme Darko Beyond the Horizon se Akobi oblači zahodno, medtem ko si njegova žena Mara tega ne more privoščiti.

Tisti moški, ki so bili kot on vsi v hlačah s tankimi črtami, tankih kravatah in Beatles škornjih, in njihove ženske, ki so se jim bleščali pobarvani obrazi, kričeče rdeče ustnice in sijoče zglajeni lasje; to je bil njegov svet in jaz s svojimi starimi oblačili, skodranimi lasmi in starimi natikači iz gume nisem sodila vanj. ${ }^{6}$

Akobijevi Beatles čevlji so njegov ponos in fetiš. Ko Mara izve, da bo odpotovala v Evropo, ji zrase samozavest do te mere, da si prvič upa sprehajati okoli vladnih uradov, oblečena po zahodni modi, $\mathrm{v}$ rdečo obleko in $\mathrm{z}$

5 "My dancing compressed itself into rigid, tentative gestures. I did not stop completely, but gatherings were much less fun after that and made me feel terribly self-conscious." (Dangaremgba, 1988, 42)

6 "Those males who like him were all in pencil-striped trousers, thin ties and Beatles boots, and their females who all glittered in their painted faces, their screaming red lips and their gleaming straightened hair: that was his world, and I with my old clothes, kinky hair and old tyre-slippers, didn’t belong in it.«(Darko, 1995, 26) 
razčesanimi lasmi. Za pot v Evropo si prvič v življenju obleče kavbojke in pulover, obuje superge ter se poti od vročine in ponosa nad svojo podobo. Obleka spremeni človeka in $\mathrm{v}$ romanu avtorica $\mathrm{v}$ ironičnem tonu izkušene pripovedovalke razpreda o svoji karikaturi psevdoevropreobrazbe, ki jo je napolnila s psevdosuperiornim občutkom (Darko, 1995, 55). Mara je poosebljena naivnost, kot jo ob različnih priložnostih označita tudi prijateljici. Misli, da je z obleko postala nov človek, a obleka ni dovolj za njeno duhovno preobrazbo ali dozorevanje, ta pride kasneje in sčasoma ter nima opraviti le z oblačili.

Nekatere junakinje v literaturi afriških pisateljic pa se vračajo iz tujine, Zahoda (Evrope, Amerike), domov v svojo deželo v Afriki, kjer zaradi sprememb, ki jih prinašajo neokolonizacijski vplivi, in njihovega spremenjenega, izkušenejšega pogleda, doma ne prepoznajo več. Junakinja se vrne domov, da bi našla »dom «, toda namesto tega spozna, da je bila njena vizija romantično utopična, da je postala razseljena oseba. V zgodbi »Everything Counts« se pripovedovalka v Afriko vrne $\mathrm{z}$ izkušnjo Zahoda in tujstva, ki zaznamuje njeno dojemanje svoje dežele. Izkušnja odhoda v tujino jo zaznamuje in spremeni njen pogled. Ne spozna le Evrope, temveč se redefinira njen pogled na dom, deželo, kulturo ali Afriko na splošno, nenazadnje pa tudi nase, in vpliva na oblikovanje identitete. Afrika in Gana postaneta pri izseljeni junakinji paradigma za dom. Sissie se sooči s spremembami, ki so se zgodile $v$ njeni deželi in pričajo o neustavljivem razraščanju zahodnih vplivov $\mathrm{v}$ javne in zasebne pore afriškega vsakdana. Med njeno odsotnostjo se čas v Afriki ni ustavil. Družbene spremembe, ki se dogodijo in jih pripovedovalka s svojim novim pogledom tudi bolje vidi, so povezane z nekritičnim prevzemanjem zahodnih vrednot. Pripovedovalkin kritični pogled je osredotočen predvsem na afriško željo »biti bel/a« oziroma na pozunanjene oblike te želje, ki se izražajo pri vseh predstavnikih družbe. Še posebej je ogorčena nad njenim vplivom na žensko identiteto. Junakinja opazi, kako se "zahodnost « pri ženskah povnanja; ženske skorajda brez izjeme nosijo lasulje z dolgimi valovitimi lasmi ter si kožo belijo s kremami, ki na obrazih puščajo lisaste madeže. Vprašanje, ki se ji ves čas zastavlja, je, kako da Afričankam tako primanjkuje samozavesti.

Sissie je vztrajna in nema, ves čas zunanja opazovalka. Želela se je vrniti domov v »črno Afriko«, a doma črnskosti ni našla, o čemer se ni mogla 
z nikomer pogovoriti. »Ni se želela počutiti bolj tujka, kot se je že - ko je videla, da je bila v vsem mestu edina črnka. " ${ }^{7} \mathrm{~V}$ zgodbi se torej odpira tudi vprašanje rasne identitete oziroma črnskosti, kdo je pravzaprav zares črn in kako se črnost in črnskost izražata; ničesar nimata opraviti z dejansko barvo kože, temveč le z občutkom ter identitetno in kulturno pripadnostjo. Najbolj »črna« se čuti Sissie, ki je svojo črnskost definirala z izkušnjo tujstva na belem Zahodu. Junakinja razmišlja, kaj so prave črnske vrednote in se definira s panafriškim sloganom »biti črn je čutiti se črn", ki izhaja iz ideje, da si vsi, ki so afriškega porekla, delijo skupno zgodovino, kulturo ter izkušnjo in naj zato držijo skupaj. Sissiejin nacionalizem je podkrepljen z izkušnjo tujine. Hkrati se njen bolj izraženi nacionalistični čut in pripadnost ujemata $\mathrm{z}$ njeno žensko identiteto. Sissie se vrne v Afriko kljub možnosti, da ostane na Zahodu, za razliko od izobraženih moških (tudi njen mož v času zgodbe še malo popotuje naokoli), ki ostajajo na Zahodu, kjer je življenje perspektivnejše. Moški ostanejo v tujini, ker jih misel na vrnitev domov spravlja v strah. Sissie, ki se veseli vrnitve v domovino, je ob stiku z resničnostjo iz dneva $\mathrm{v}$ dan bolj razočarana. Konec zgodbe prinese grenko spoznanje, da so imeli njeni črni bratje morda prav, ko so ostali v tujini, navsezadnje jim mora pritrditi. Odpirajo se dileme, kako se doma ponovno integrirati, ko si že postal etablirana diaspora, dileme doma in navsezadnje identitete, afriške in ženske, ki se tudi v afriški stvarnosti raztaplja $\mathrm{v}$ toku asimilacije.

Tudi v romanu Nervous Conditions se junakinja Nyasha zaradi svoje dvojne izkušnje (rodila se je v Zimbabveju, zgodnje otroštvo preživela $\mathrm{v}$ Angliji in se nato vrnila $\mathrm{v}$ Zimbabve) $\mathrm{v}$ domovino ne zmore več identitetno umestiti. Ta vmesni prostor lahko poimenujemo tudi nedomovinskost (Potocco, 2001, 17-38), in sicer po izrazu unhomely, ki ga je uvedel Homi Bhabha. Ponazarja položaj izvrženosti iz domovanja, premik iz »zasebnosti«, ko so meje med domom in svetom zabrisane oziroma težko določljive ter postane zasebno del javnega in nasprotno. Bhabha se osredotoča na literarne trenutke, kjer je enačenje pojma identitete $\mathrm{z}$ domom prekinjeno. Unhomely označuje nezmožnost varne osebne kontinuitete in identifikacije z

7 "She did not want to look more of a stranger than she already felt - seeing she was also the one black girl in the whole city.« (Aidoo, 1970, 4) 
danimi kulturnimi idejami domovanja. Proces, ki ga Bhabha uporablja kot etnično kategorijo, lahko služi kot izkustvo sleherne izvrženosti iz doma, iz kolonialne pa je prenosljiv tudi $\mathrm{v}$ feministično terminologijo in označuje tudi ženski subjekt.

Sissie v romanu Our Sister Killjoy in junakinja Sissie v kratki zgodbi »Everything Counts« sta doma v Afriki oziroma Gani. Obe junakinji odideta $\mathrm{v}$ tujino in se vrneta s kritičnim pogledom na svojo deželo in ljudi, ki se pustijo pretirano kolonizirati $\mathrm{v}$ navadah in načinih, ki jih povzemajo od belcev. Čeprav sta junakinji enako kot avtorica Ama Ata Aidoo kritični do svoje dežele in domačih, sta jim vdani, ker Afrika ostaja dom, kakorkoli že problematičen, medtem ko Zahod ne more dom nikoli postati.

\section{Izven Afrike}

Književnosti afriških pisateljic, kjer je glavna ali stranska tema zgodbe potovanje ali bivanje junakinje v tujini, je skupno, da je tujina - Evropa ali Združene države Amerike - predstavljena kot protipol bolj ali manj prijaznemu domu - Afriki. Tujina je velik mit, enoznačen z urbanizacijo, razvojem in finančnim vložkom, ki so ga v afriške dežele prinesli kolonizatorji.

$\mathrm{V}$ romanih afriških pisateljic pogosto sledimo navezavi in potovanjem $\mathrm{v}$ dežele nekdanjih kolonizatorjev, pa naj gre za anglosaksonske, frankofonske ali luzofonske prostore, in povezavi afriške dežele $\mathrm{z}$ njeno nekdanjo kolonijo. Potovanje je privilegij, možnosti migracij so za številne Afričane in še bolj za Afričanke redke, poti so zaprte, predvsem zaradi slabih ekonomskih in političnih predispozicij dežel in posameznikov. Vez z Evropo včasih poteka $\mathrm{z}$ možnostmi izobraževanja ali pa je junakinja pripadnica premožnejšega urbanega sloja. Potovanje Afričanov v tujino se nemalokrat konča $\mathrm{s}$ stalnim bivanjem $\mathrm{v}$ njej in $\mathrm{z}$ odrekanjem afriški identiteti, $\mathrm{z}$ nekakšno kulturno amnezijo in prevzemom zahodnih navad, ki so jih $\mathrm{v}$ lastni deželi naredile za tujce. V romanu Zenzele Nozipo Maraire je prototip takšnega neuspeha obetajoči Mukoma Byron, ki se vrne domov na obisk kot tragikomična angleška karikatura brez izobrazbe, po katero je šel, poln angleških navad in z belo ženo, predvsem pa sramujoč se svojega porekla, 
sorodnikov in preteklosti, misleč, da se lahko za vse odkupi z denarjem. Ves roman je napisan kot pismo matere hčerki, kot pričevanje o njenem afriškem poreklu, namenjeno temu, da bi ohranila stik $\mathrm{z}$ afriško identiteto. Potovanje v Združene države Amerike ni cilj, temveč začetek. Končni cilj je vrnitev domov v Afriko, ki jo je zapustila. Mati Shiri pravi svoji hčeri, ki odhaja na študij na ameriški Harvard:

Prosim, zapomni si, da tvoj prihod pomeni začetek, ne konec tvoje poti. To je dolga in izzivov polna pot. Tam si popotnica, mimohodnica ... Tvoje državljanstvo je dvojno, celo globalno ... Zapomni si, da je tvoj končni cilj dom, ki si ga zapustila. Afrika bo to, kar boste ti in drugi iz nje naredili. Brez vas je nič. ${ }^{8}$

Po mnenju Zenzeline matere državljanstvo njene hčerke ni le afriško, ne izhaja iz panafrikanistične nacionalistične ideologije. Državljanstvo je dvojno, globalno, pravi. Priznava hčerino razseljenost oziroma diasporo in verjetno je ta bojazen vzvod za pisanje pisem o osebni, družinski in afriški politični zgodovini, ki se zaokrožijo v roman.

Junakinje v »potovalnih « romanih identitetno oblikuje pot ali bivanje v tujini. Sissie v romanu Our Sister Killjoy in Mara v romanu Beyond the Horizon odpotujeta v Evropo, v Nemčijo, Sissie kasneje še v Anglijo. Drugačen primer je Nyasha v romanu Nervous Conditions, ki se ob začetku romana vrne iz Anglije, kjer je s starši preživela del otroštva. Ta dihotomija izkušnje bivanja tam in spet doma jo zaznamuje, da skozi roman posledično spremljamo njen identitetni problem.

Ob motivu Zahoda oziroma Evrope se v romanih odpira vprašanje Evrope kot mita, stereotipa in realnosti. Realnost se manifestira prek osebnega izkustva posameznih junakinj, ki je raznoliko glede na okoliščine obiska in osebnih predispozicij, ter podobno $\mathrm{z}$ rasnega stališča, ko se soočijo s svojo fizično drugačnostjo oziroma fizično drugačnostjo belcev. Sissie, glavna

8 "Please remember that your arrival marks the beginning, not the end, of your journey. It is a long and challenging trip. You are a sojourner there, just passing through. ... You ... have dual citizenship, even global citizenship.... Remember that your ultimate destination is the home that you have left. Africa will be whatever you and others like you make of it. Without you, it is nothing." (Maraire, 1996, 70-71) 
junakinja romana Our Sister Killjoy, je izobražena in razgledana ter ima od vsega začetka kritičen, intelektualno distanciran odnos do tujine, Evrope, zahodne civilizacije in njenih vrednot na splošno. Je privilegirana posameznica in se tega tudi zaveda, do tega pa zavzame kritično, včasih ironično distanco, ki je posebej razvidna, ko nesočutno sprejema navdušene odzive rojakov ob svojem odhodu. V Evropo odhaja kot gostja, tja je povabljena kot afriška študentka. Kot pravi kasneje svoji nemški prijateljici: »Marija, bil je čas, ko je bilo modno biti Afričan. Splačalo se je biti afriški študent. In če si bila afriška študentka s popotniškim duhom, si potovala. $\ll^{9}$ Sissie je imela možnost izkoristiti evropsko gostoljubje, ki bi ga morda lahko imeli za odkupovanje starih grehov.

Mara, junakinja romana Beyond the Horizon pisateljice Amme Darko, je njeno nasprotje. Ne le da ne premore osnovne izobrazbe, je nepismeno dekle iz vasi, ki ne kaže pravšnje elastičnosti, ko je treba razmišljati s svojo glavo. Mara je preveč ujeta v nesrečni splet tradicionalne vloge, ki jo navaja $\mathrm{k}$ popolni podrejenosti očetu in kasneje možu, ter slepe vere $\mathrm{v}$ zahodne mite in stereotipe, ki naj bi jo odrešili, predvsem z ekonomsko osvoboditvijo - z denarjem. Vse to je povezano z željo, da bi bila ljubljena, saj živi v partnerskem odnosu kot žrtev nasilja in zlorabe. Vsakokrat, ko skuša prevzeti nadzor nad svojim življenjem, jo ustavi mož, ki mu je zvesto pokorna, noče se upreti, zato zamudi vsako priložnost, da bi s pametno osebno odločitvijo naredila odrešujoč preobrat in se rešila jalovega partnerstva.

Sissie prihaja v Evropo na popolnoma drugačen način kot Mara. Prihaja skozi glavna vrata, Evropejci jo povabijo, organizirajo program dejavnosti in krijejo potne stroške. Sissie je privilegirana in izobražena ter predstavlja mladi afriški potencial. Mara prihaja iz tradicionalne vasi, mož pa jo je pripeljal $\mathrm{v}$ predmestno barakarsko naselje, kjer živi v razmerah, ki bi tudi njeno mater $\mathrm{z}$ vasi spravile v osuplost. V Evropo se odpravi, ko pošlje ponjo mož, ki je tja odšel pred njo, a ne iz romantičnih vzgibov, kot si domišlja Mara. V Evropo pride nezakonito, pot pa ji plačajo in organizirajo ljudje, ki se ukvarjajo $s$ trgovino s spolnostjo. Prek meje pride s tujim potnim listom, saj belci ne

9 »Marija, there was a time when it was fashionable to be African. And it paid to be an African student. And if you were an African student with wanderlust, you travelled.« (Aidoo, 1977, 59) 
razločijo različnosti potez na črnskih obrazih. Mara se znajde v vlogi prebežnice in kmalu prostitutke, Sissie pa v Evropi sprejmejo odprtih rok; dovolj je privilegirana, da je lahko kritična. Sissie potuje naokoli, Mara pa je zaprta $\mathrm{v}$ stanovanje, njeno nepoznavanje jezika in okolja ji odvzame še zadnje krpice lastne svobode in življenja, ki jih je doma v Gani brez moža še imela.

Vizija Evrope je v Sissiejinih očeh ves čas pod kritičnim drobnogledom in obravnavana $\mathrm{z}$ ironično distanco. Sissie ne premami vloga privilegirane osebe, ves čas se kritično sprašuje, zakaj ji namenjajo toliko pozornosti. Ko razmišlja o Evropi in svojem potovanju, se takoj zave, da jo Evropejci vabijo, da bi se oddolžili za grde stvari, ki jih je Afriki naredil njihov kolonializem:

Daleč je od doma do Evrope. Kruta preteklost, čudna sedanjost, večja puščava ali dve, morje, ocean, več različnih jezikov narazen, letala premoščajo nebo ... Njeno potovanje je moralo imeti kaj opraviti s človeškim trudim, »da bi se spet spravili.$^{10}$

Seveda pa njenega uspeha kot vstopnice v Evropo ne občudujejo le Evropejci, temveč tudi njeni rojaki. Do njih je Sissie še posebej ironična. Prav nič je ne gane vzhičenost nekega Afričana na sprejemu, ki je v Evropi že bil in je o tej oddaljeni deželi govoril z glasom, »mokrim od hrepenenja«, da »ima neverjetno srečo, da so jo izbrali«, in »da je potovanje v Evropo nekakšna generalka za potovanje v raj« (Aidoo, 1977, 9).

Ta kritičnost do Afričanov, ki Evropo nereflektirano vidijo kot uresničitev svojih sanj, se pri pisateljici Ami Ati Aidoo pojavi večkrat, pri njeni junakinji Sissie pa je kasneje vzrok osebne žrtve, razhoda z ljubljenim partnerjem. Različni pogledi na Zahod in njegov pomen za Afričane ju ključno ločujejo.

Marina zgodba je drugačna. $Z$ vasi pride $\mathrm{v}$ mesto $\mathrm{z}$ možem, kot nevesto jo kupi njegov oče, moža pred tem ni poznala. Njenemu očetu je mar le za

10 "It is a long way from home to Europe. A cruel past, a funny present, a major desert or two, a sea, an ocean, several different languages apart, aeroplanes bridge the skies. ... Her journey must have had something to do with a people's efforts 'to make good again' ..." (Aidoo, 1977, 8). 
denar, ki mu ga bo prinesla nevestnina. Marin mož razume pridobitev žene kot ekonomsko transakcijo in si Maro priskrbi le za gospodinjske usluge, še seksualne so mu bolj odveč kot ne. Maro zlorablja, zanemarja in pretepa. Skratka, Marin odnos z možem in njena želja, da bi ga zadovoljila, ves čas ne vodita nikamor. Nato mož odpotuje $v$ Evropo in čez čas pošlje po Maro. Čeprav se Mari s tem moškim nikoli ni zgodilo nič dobrega, njeno upanje $\mathrm{v}$ ljubezen in idealistična vera $\mathrm{v}$ romantičen razplet ne usahneta, kaj šele napeljeta na misel, da se morda ne bo vse najbolje izteklo. Evropa je namreč zanjo raj, dežela »zdravnikov in pravnikov«, končni cilj vseh pričakovanj. Je ekonomska rešitev, da ne rečemo bogastvo.

Bila sem na poti v deželo belcev. Videla bom deželo, ki jo gledajo veliki zdravniki in odvetniki, kamor ministri potujejo s svojimi ženami in prijateljicami, deželo, za katero sem nekoč mislila, da je tako daleč in tako blizu nebes, da si nisem niti drznila pomisliti nanjo. To je bila dežela, kamor bom stopila pred začetkom novega dne. In občutek je bil krasen. ${ }^{11}$

Prav tako je potovanje v Evropo dvignilo Marin status med ljudmi, predvsem v družini in skupnosti na vasi. Vse to je vplivalo na njeno samozavest. Pričakovanje in zavist, ki jo je zbujala med svojimi ljudmi, sta v njej porajali verjetno najlepše občutke, kar jih je doživela. Bila je v središču pozornosti in cenjena, bolj v nebesih kot kadarkoli poslej. Ironični podton pripovedovalke nam predstavi vzhičenost pripravljalne mrzlice za pot v Evropo kot nekaj absurdnega. Pripovedovalka namreč že ve, da Maro v Evropi ne čaka nič, česar bi se lahko veselila.

Potovanje v Evropo je dvignilo moj ugled $\mathrm{v}$ družini na vasi do te mere, da je bilo materi vseeno, ker je morala prodati svoje dragoceno okrasje. [...] Toda nečesa sem se naučila hitro. Tako dramatično so se lahko stvari spremenile, tako čarobno je lahko Evropa delovala na njihov odnos. [...] Tako kot je vplivalo na

$11 » I$ was on my way to the whiteman's land. I was going to see the land that the big doctors and lawyers see, where the Ministers travel with their wives and girlfriends, the land I once thought was so far away and so near heaven I dared not even think about it. This was the land my feet would step upon before the breaking of the another day. And the feeling was great." (Darko, 1995, 58) 
odnos ljudi, je vplivalo na mojo samozavest. [...] Jaz, nepismena Mara, sem se spremenila v moderno žensko $s$ telesom in dušo; karikatura psevdoevropreobrazbe, ki je s seboj prinašala karikaturen psevdopomemben občutek. Počutila sem se prerojeno. ${ }^{12}$

Sissiejino potovanje v romanu Our Sister Killjoy ni popotništvo, je organiziran izlet. Njen prvi stik z Evropo je Frankfurt, prvi stik z okolico pa pogled na izložbe. Nenadoma se zave, od kod prihajajo potrošne dobrine, ki navdušujejo toliko ljudi doma, le da je tukaj tega še milijonkrat več in je milijonkrat boljše. Prve stvari, ki jih poleg velikih količin potrošnih dobrin in hrane Sissie v Nemčiji opazi, so mediteranski, zanjo eksotični sadeži, kot je tropsko sadje eksotično za Evropejce. Nemčijo si zapomni po okusu sliv in hrušk ter množici starih gradov.

Sissie se prvič zave svoje fizične oziroma rasne drugačnosti, ko zasliši nemško deklico materi reči: »Schwarze Fräulein.«A je preveč osveščena in izobražena, da bi to razumela kot kaj ponižujočega. Prav nasprotno, drugačnost, razlika v barvi kože, jo napelje na misel, da se ji belci zazdijo grdi, in to je tisto, zaradi česar obžaluje, da se je z razliko soočila.

Tokrat se je pošteno ozrla naokoli. In jo je zadelo:

vsa gruča ljudi, ki so prihajali in odhajali v vse smeri, je bila barve vloženih koščkov svinjine, ki je iz tujine prihajala na njihove tržnice.

Parklji, prašičji repki, prašičja ušesca.

Gledala je, gledala toliko teh kož.

In šlo ji je na bruhanje.

Potem se je sramovala svojega odziva.

Nekaj v njej se je stisnilo.

12 "That I was travelling to Europe raised me in the esteem of my family in the village so much that mother didn't care any longer about the beads she had to sell. ... But one thing, though, was that I learnt fast and quick. So dramatically could things change; so magically could Europe work on attitudes. ... Just as it affected people's attitudes, so too did it affect my confidence. ... I illiterate Mara, had turned into a modern woman, body and soul; a caricature pseudo-Eurotransformation that brought with it its caricature pseudo-high feel. I felt a new me.« (Darko, 1995, 54-55) 
Do konca življenja bo obžalovala trenutek, ko je morala opaziti razlike v človeški obarvanosti. ${ }^{13}$

Tudi Mara se kmalu sooči s svojo drugačnostjo in demistifikacijo Evrope. Že ob prihodu na nemško letališče mejo prečka s potnim listom druge črnske ženske, saj so belcem vsi črnski obrazi enaki. Na vlaku njen spremljevalec $\mathrm{v}$ podkrepitev rasnega stereotipa uporabi opičji režeči obraz, da odžene druge potnike kupeja. Moževa nemška žena Gitte ima izoblikovane stereotipne podobe o Afričanih: vraževerni, nevzgojeni in grobi. Toda tega Afričani ne skušajo spremeniti. »To izkoristimo sebi v prid, « pravi Ossey (Darko, 1995, 102).

Mara pride v Evropo s svojimi stereotipi, na primer podobo zahodne ženske, ki je visoka, dolgonoga, svetlolasa, $\mathrm{z}$ modrimi očmi in dolgimi nalakiranimi nohti, kakršne je videla doma v filmih. Ob prihodu se mit o zahodni lepoti oziroma lepoti belopoltih žensk takoj sesuje, in sicer ob pogledu na majhno in debelušno Akobijevo nemško ženo Gitte. Kmalu spozna, da Afričani v Evropi spreminjajo svojo identiteto, ime in način oblačenja. Njen mož Akobi se v Nemčiji preimenuje v Cobbyja, ker se mu novo ime zdi bolj civilizirano in moderno, Akobi pa zveni preveč primitivno. Kot pravi njegov prijatelj: »Kako naj rečem, afriško, ja, preveč afriško ... zato ga je začinil z nekaj eh ... recimo temu evropeizma. «14

Po drugi strani Sissie ohranja svoje afriško ime, čeprav ji je uradno ime Marie. Toda Sissie je eden od redkih primerov, kjer se je originalni koncept

13 "So she looked around her, really well this time.

And it hit her. That all that crowd of people going and coming in all sorts of directions had the colour of the pickled pig parts that used to come from foreign places to the markets at home.

Trotters, pig-tails, pig-ears.

She looked and looked at so many of such skins together.

And she wanted to vomit.

Then she was ashamed of her reaction.

Something pulled inside of her.

For the rest of her life, she was to regret this moment when she was made to notice differences in human colouring." (Aidoo, 1970, 12)

$14 » .$. how shall I say it, too African, yes, too African. ... Which is why he flavoured it with a bit of eh ... let's say, Europeanism.« (Darko, 1995, 66) 
iz starih časov uspešno uveljavil v angleščini. Sissie je ljubkovalni izraz za sestro, posebej kadar v družini ni veliko deklic. Sissie se je ime prijelo, ker je bila skupaj v šoli z veliko dečki.

Tako Sissie kot Mari se razkrije, kako živijo Afričani v Evropi. Biti študent je pogosto krinka. Tako Marino kot Sissiejino potovanje v Evropo je na neki način povezano $\mathrm{z}$ njunimi razmerji s partnerji oziroma $\mathrm{z}$ razvojem odnosov, na katere vplivajo okoliščine. Marino potovanje je enosmerna vozovnica v pekel, saj je zlorabljena žrtev trgovine s spolnostjo.

Mara mora priti v Evropo, da sprevidi svojo izkoriščanost. Šele tu se ji zasvita, da $v$ njenem življenju ni vse prav. $Z$ razbitjem številnih stereotipov pride tudi do osebnih spoznanj. V Evropi se zanjo nič ne spremeni, niti v odnosu njenega moža (popolna podrejenost in odvisnost sta še večji, saj je sedaj v okolju, kjer nikogar ne pozna) niti ne zna jezika. Tudi tu se ne more rešiti uničujočega partnerskega odnosa. »Da afriški moški v Evropi prav tako pretepajo svoje žene, ni sodilo v lepo sliko evropskega življenja. Bila sem v Evropi, da, toda še vedno nisem spoznala Evrope. « ${ }^{15}$

Sissiejino bivanje v Evropi je tudi boleče razkrivanje moškega izkoriščanja in dokončne osamosvojitve, vsaj od moža, če že ne od patriarhalne represije, ki rezultira v izkoriščanje naivnih žensk, kot je sama. Sissiejina partnerska zveza je zveza ljubezni in ne tradicionalnega dogovora med očetoma kot pri Mari. Sissiejin ljubezenski odnos in njegov razplet sta neločljivo povezana s političnostjo, Zahodom, posledicami kolonializma ter predvsem $\mathrm{z}$ različnostjo pogledov na družbene razmere, ki ju posledično ločijo oziroma jima fizično onemogočijo, da bi ostala skupaj. V ljubezenskem pismu Sissie poda kritiko zahodne civilizacije. Je idealistična nacionalistka in bojevnica ter pomanjkanje zanosa očita številnim afriškim izobražencem (nenazadnje tudi svojemu partnerju), ki po študiju ostanejo na Zahodu.

Sissie in njen ljubimec se razhajata v političnih pogledih. Od njega je pričakovala, da se bo po koncu študija vrnil domov v Afriko, saj je to njegova moralna zaveza. Toda odšel je naprej in se ni vrnil, Sissie pa se je vrnila. Ločile so ju celine. Ločila ju je različnost političnih pogledov. Ločila ju je

15 »That African men also beat their wives in Europe somehow didn't fit into my glorious picture of European life. I was in Europe, yes, but I still didn't know Europe." (Darko, 1995, 73) 
kolonizacija. Sissie postavi politično vzporednico: »... negativizem ... je kot ekspanzija zahodne civilizacije v modernem času, ker zaduši vse življenje in celo uniči ... cele rase ljudstev na poti rasti ... $\aleph^{16} \mathrm{Njen}$ dragi intelektualni sogovornik misli, da je treba pustiti času, da se premika, Sissie pa meni, da je čas predragoceno vozilo, da bi se premikalo brez pravega tovora, česa, kar bi premikalo za nas.

Roman Our Sister Killjoy je strukturiran kot vzvratno potovanje iz Afrike $\mathrm{v}$ Evropo in raziskuje rasne in seksualne parametre z možnostmi ljubezni (Kadiatu, 1998, 152). Sissie, ki je nekakšna predstavnica Afričank, potuje prek čudnih pokrajin Evrope in se znajde na ozemlju, v katero so vtisnjeni zgodovinski dogodki. Potuje skozi osebne občutke odtujitve v Nemčiji, ki se prostorsko ne more ločiti od bolečih zgodovin. Pogrezne se v srce moraste evropske slike, kjer jo njena "protizahodna nevroza« uči, da se belost osredotoča in objektivizira kot rasno razliko (ibid., 153).

Zgodovine imperializma in realnosti rasizma ter eksploatacije ležijo pod Sissiejino analizo interkontinentalne migracije in interrasnega ženskega prijateljstva. $\mathrm{V}$ romanu pride do preobrata $\mathrm{v}$ pozicijah moči, tako na narativnem nivoju kot $\mathrm{v}$ smislu medosebnih in medrasnih razmerij, ko Ganka Sissie, »tujka v deželi«, v prijateljstvu z »domačinko«, Nemko Marijo, prevzame pozicijo moči oziroma odločanja, moške odmaknjene vloge nad Marijino žensko čustveno odvisnostjo.

Pripoved promovira afriško žensko subjektiviteto na mesto opazovalke, zgodovinske razsodnice. Sissie kritično ocenjuje evropsko zgodovino, navade, pokrajino, ljudi in jezik, z njenim pogledom govori smešno "golobjo « angleščino Marija in ne Sissie. Na tem mestu pride do feminističnega preobrata, ki se prepleta s kulturnimi (ne)umestitvami. „Črnski feminizem« v razmerju do tega teksta je reevalvacija afriške ženskosti v razmerju do afriških skupnosti in moških ter ponovna preučitev rasnih in kulturnih razlik med ženskami (Kadiatu, 1998, 154).

$16 »$...negativism ... must be like the expansion of western civilisation in modern times, because it chokes all life and even eliminates whole races of people in its path of growth ..." (Aidoo, 1977, 112) 
Če junakinji primerjamo, lahko ugotovimo, da sta obe Ganki, obe odpotujeta v Nemčijo, Sissie kasneje še v Anglijo. A Nemčiji, ki ju junakinji doživita, sta si različni. Sissiejina Nemčija spominja na tisto iz turističnih prospektov, Marina iz melodram. Njuni izkušnji sta primerljivi v (prvih) soočenjih s svojo rasno drugačnostjo. Zgroženost in osuplost ob barvah kože in vedenjih, ki opominjajo na netolerantnost in nepoznavanje različnosti, njunemu identitetnemu oblikovanju doda novo dimenzijo, ki je v afroameriških romanih pogostejša. Drugačnost, rasna in kulturna, vpliva na njune stike z belci, pri Sissie z Marijo, pri Mari pa z Akobijevo nemško ženo; obe si ob njiju želita bolje spoznati Afriko ali utrditi že pričakovane, morda tudi napačne predstave.

\section{Namesto zaključka}

V literaturi sodobnih afriških pisateljic se Afrika spreminja s (post)kolonializmom, razraščanjem mest, redefiniranjem tradicionalnega in mešanjem tradicionalnega ter modernega. Predvsem tranzicija, transformacija, mešanje starih in novih vrednot, ponekod pa tudi razkrajanje tradicije in nekritično prevzemanje zahodnega, je temeljna izkušnja, ki jo afriške pisateljice v svojih literarnih delih pogosto vključujejo kot temo in motiv. Eno od poglavitnih stičišč je kritika Zahoda, zahodnih vrednot in načina življenja, ki pronicajo $\mathrm{v}$ afriški prostor in preplavijo vse ravni življenja. Literaturo uporabljajo za aktualizacijo težav, s katerimi se spopadajo, za iskanje identitete afriške ženske $\mathrm{v}$ času spreminjajočih se vrednot $\mathrm{v}$ prepletu postkolonialnih in tradicionalnih sistemov.

Ob branju literature afriških pisateljic lahko dekonstruiramo mit potovanja kot izključno moški privilegij. Izbranke potujejo na Zahod, v dežele nekdanjih kolonij in $\mathrm{v}$ Združene države Amerike. Ta potovanja sprožajo dileme in prevpraševanja o razseljenosti Afričank, definiranje in redefiniranje podobe Zahoda in doma ter navsezadnje tudi (afriške) ženskosti.

Potovanja lahko odsevajo nemirnost junakinj, nepristajanje na konvencije in nomadsko občutenje. Predvsem afriške mestne izobraženke so pogosto takšne na videz samozavestne, a izgubljene potnice, ki s fizičnim 
premikanjem in neustaljenostjo bolj ali manj uspešno razvijajo tudi svojo duhovnost ter iščejo in definirajo svoje (razcepljene) hkratne identitete: žensko in zelo pogosto rasno ali etnično. Metafizična potovanja so večsmerna, v preteklost kot iskanje doma, kot beg iz realnosti, v sedanjost kot iskanje novih spoznanj, povezanih s preteklo in sedanjo izkušnjo, ali kot želja, ki se manifestira v fiktivni prihodnosti. Junakinja klasično pojmovanje osvoboditve sprva razume kot fizični in duhovni odmik od doma in nato $\mathrm{z}$ duhovnim razvojem pride do miselnega preobrata, v katerem spozna, da je osvoboditev etnično in nacionalno osveščanje, da so njena ječa pravzaprav (post)kolonialni vplivi in pritiski, ki se jih osvobaja $\mathrm{z}$ redefiniranjem pomena doma in vračanjem $v$ prevrednoteni afriški dom.

\section{LITERATURA}

\section{Literarna dela}

Aidoo, Ama Ata: No Sweetness Here, Longman African Writers, Essex, 1970.

Aidoo, Ama Ata: Our Sister Killjoy, Longman African Writers, Essex, 1977.

Aidoo, Ama Ata: Changes - a love story, The College Press, Harare, 1991.

Dangaremgba, Tsitsi: Nervous Conditions, The Seal Press, Seattle, 1988.

Darko, Amma: Beyond the Horizon, Heinemann African Writers' Series, Oxford, 1995.

Darko, Amma: The Housemaid, Heinemann African Writers' Series, Oxford, 1998.

Emecheta, Buchi: The Joys of Motherhood, Heinemann African Writers' Series, Oxford, 1979.

Maraire, J. Nozipo: Zenzele, A letter for my daughter, Delta, New York, 1996. 
Vera, Yvonne (ur.): Opening Spaces, Heinemann African Writers' Series, Oxford, 1999.

\section{Razprave, članki, knjige}

Amadiume, If: Reinventing Africa, Matriarchy, Religion and Culture, Zed Books, London, New York, 1997.

Ashcroft, Bill, Griffiths, Gareth, Tiffin, Helen (ur.): The Empire Writes Back: Theory and Practice in Post-Colonial Literatures, Routledge, London, 1989.

Bhabha, Homi, K.: »Dissemination: Time, Narrative and the Margins of the Modern Nation «, v: Nation and Narration, Routledge, New York in London, 1990.

Bhabha, Homi, K.: The Location of Culture, Routledge, London, 1994.

Bowlby, Rachel: »Domestication«, v: Elam, Diane, Wiegman, Robyn (ur.), Feminism Beside Itself, Routledge, New York in London, 1995.

Braidotti, Rosi: Nomadic Subjects: Embodiment and Sexual Difference in Contemporary Feminist Theory, Columbia University Press, New York, 1994.

Collins, Hill, Patricia: Black Feminist Thought, Knowledge, Consciousness, and the Politics of Empowerment, Perspectives on Gender, Volume 2, Routledge, New York, London, 1990.

Coquery-Vidrovitch, Catherine: African Women, A Modern History, Westview Press, Boulder, Oxford, 1997.

Časopis za kritiko znanosti, letnik XXIX, 2001, št. 204-205-206: Afrike, Študentska založba, Ljubljana, 2001.

Davies, Boyce, Carole: Black Women, Writing and Identity, Migrations of the Subject. Routledge, London in New York, 1994.

Davies, Boyce, Carole, Ogundipe-Leslie, Molara: Moving Beyond Boundaries, Volume 1: International Dimensions of Black Women's Writing, New York University Press, New York, 1995. 
Davies, Boyce, Carole: Moving Beyond Boundaries, Volume 2: Black Women's Diaspora, New York University Press, New York, 1995.

Egejuru, Phanuel, Akubueze, Phanuel, Katrak, Ketu, H. (ur.): Nwanyibu, Womanbeing and African Literature, Africa World Press, Trenton, NJ, Asmara, Eritrea, 1997.

Felski, Rita: Beyond Feminist Aesthetics, Feminist Literature and Social Change, Harvard University Press, Cambridge, Massachusetts, 1989.

Friedman, Stanford, Susan: Mappings, Feminism and the Cultural Geographies of Encounter, Princeton University Press, Princeton, New Jersey, 1998.

Gates, Henry, Louis Jr., Appiah, K., Anthony (ur.): Reading Black, Reading Feminist, A Critical Anthology, Meridian/Penguin Books Ltd., New York, 1990.

Greene, Gayle, Kahn, Coppélia: »Feminist scholarship and the social construction of woman «, v Greene, G., Kahn C. (ur.), Making a Difference, Feminist Literary Criticism, Routledge, London in New York, 1994, str. $1-7$.

Holloway, Karla, F., C.: Moorings and Metaphors, Figures of Culture and Gender in Black Women's Literature, Rutgers University Press, New Brunswick, New Jersey, 1992.

Hooks, Bell: Talking Back: Thinking Feminist, Thinking Black, South End Press, Boston MA, 1989.

Hrastnik Natalija: Oblikovanje identitete $v$ literaturi afriških in afroameriških pisateljic.

Doktorska disertacija, Filozofska fakulteta, Ljubljana, 2002.

Hrastnik, Nataša: »Other Rooms - African Women’s Writing«, v: FAMI, Body and Difference, 1/I., 2000, Frakcija, Maska, Zagreb, Ljubljana.

Hrastnik, Nataša: »African women's writing - postcolonial and feminist intersections.« V: Kotjurova, Marija P. (ur.). Filologičeskie zametki. Vyp. 2: mežvuzovskij sbornik naučnyh trudov. Perm: Permskij universitet; Ljubljana: Universitet, 2003, č. 2, str. 147. 
James, Adeola: In Their Own Voices, African Women Writers Talk, James Curry Ltd., London, Heinemann, Portsmouth (N. H.), 1990.

Kanneh, Kadiatu: African Identities, Race, Nation and Culture in Ethnography, Pan-Africanism and Black Literatures, Routledge, London, 1998.

Morrison, Toni: Playing in the Dark: Whiteness and the Literary Imagination, Vintage Books, New York, 1993.

Moyana, Rosemary:»Men \& Women: Gender Issues in Tsitsi Dangaremgba’s Nervous Conditions \& She No Longer Weeps«, v: Eldred Durosimi Jones, Marjorie Jones (ur.), New Trends and Generations in African Literature 20, Africa World Press, James Currey, London, Trenton N.J., 1996.

Msiska, Mpalive-Hangson, Hyland, Paul (ur.): Writing and Africa, Longman, London, New York, 1997.

Nasta, Susheila (ur.): Motherlands, Black Women's Writing from Africa, the Caribbean and South Asia, Rutgers University Press, New Brunswick, New Jersey, 1992.

Ogunyemi, Okonjo, Chikwenye: »Womanism: The Dynamics of the Contemporary Black Female Novel in English", v: Clark, Vèvè, A., Joeres, Ruth-Ellen, B., Sprengnether, Madelon (ur.), Revising the Word and the World, Essays in Feminist Literary Criticism, The University of Chicago Press, Chicago, London, 1993.

Ogunyemi, Okonjo, Chikwenye: Africa Wo/Man Palava, The Nigerian Novel by Women, The University of Chicago Press, Chicago, London, 1996.

Olaussen, Maria: "About Lovers in Accra': Urban Intimacy in Ama Ata Aidoo's Changes: A Love Story«, v: Research in African Literatures, 33/2, 2002, str. 61-80, Indiana University Press, Bloomington.

Potocco, Marcello »Problem identitete v angleški kanadski poeziji«, Dialogi, Revija za kulturo in družbo, 2001, XXXVII, letnik 3/4, str. 17-38.

Pryse, Marjorie, Spillers, Hortense J. (ur.): Conjuring Black Women, Fiction and Literary Tradition, Indiana University Press, Bloomington, 1985.

Said, Edward, W.: Orientalizem, Zahodnjaški pogledi na Orient, Studia Humanitatis, ISH, Ljubljana, 1996. 
Squires, Judith (ur.): New Formations, The Question of 'Home', A Journal of Culture/Theory/Politics, 17, 1992, Lawrence \& Wishart, London.

Stratton, Florence: Contemporary African Literature and the Politics of Gender, Routledge, London, New York, 1994.

Tate, Claudia (ur.): Black Women Writers at Work, Oldcastle Books Ltd., Harpenden, 1983.

Werber, Richard, Ranger, Terence (ur.): Postcolonial Identities in Africa, Zed Books, London, New Jersey, 1996.

Wilentz, Gay: Binding Cultures, Black Women Writers in Africa and the Diaspora, Indiana University Press, Bloomington in Indianapolis, 1992.

ZIBF (Zimbabwe International Book Fair) (ur.): Women and Activism, ZIBF Women Writers' Conference, Harare 29-30 July 1999, Zimbabwe International Book Fair Trust, Zimbabwe Women Writers, Harare, 2000. 


\title{
THE WEST IN AFRICA AND AFRICAN WOMEN IN THE WEST: SHIFTING IDENTITY AND THE MIGRATION OF HEROINES IN THE WORK OF AFRICAN WOMEN WRITERS
}

Keywords: African women writers, African women's identity, the West, Africa, migrations, identity travels, modernity, tradition

\begin{abstract}
In the works of African women writers, Africa is seen in the grip of change - through the combined effects of colonialism and post-coloniali$\mathrm{sm}$, the growth of urbanization, the redefining of traditional culture, and the blending of the traditional and the modern. The ideas of transition and transformation, the blending of old and new values, the increasing disintegration of traditional culture, and uncritical adoption of western values all frequently underpin the plots and themes of African women writers' literature. One of the main points of convergence between their various works is a critique of the West as well as of western values and the western way of life, which have taken root in Africa and now pervade all areas of life. These writers use literature as means of bringing to the fore the difficulties that they face and as a means of exploring African women's identity in a time of changing values, in the interplay between the post-colonial and traditional systems.
\end{abstract}

